\section{ECCOMAS}

\section{Proceedia}

COMPDYN 2021

$8^{\text {th }}$ ECCOMAS Thematic Conference on Computational Methods in Structural Dynamics and Earthquake Engineering Streamed from Athens, Greece, 28 - 30 June 2021

\title{
DYNAMIC CROSS-INTERACTION BETWEEN TWO CLOSELY-SPACED SHALLOW FOUNDATIONS
}

\author{
Zeolla $^{1}$ E., de Silva ${ }^{2}$ F., Sica ${ }^{1}$ S. \\ ${ }^{1}$ University of Sannio - Benevento (IT) \\ ezeolla@unisannio.it \\ stefsica@unisannio.it \\ ${ }^{2}$ University of Naples Federico II, Naples (IT) \\ filomena.desilva@unina.it
}

\begin{abstract}
The cross interaction between two closely-spaced shallow foundations has been numerically investigated under static conditions and low-amplitude dynamic loading through a finite difference procedure implemented in the FLAC3D code. The motivation towards this research topic may be found in the increasingly growth of urbanization in modern metropolitan areas worldwide and in the urgent need for seismic requalification of vulnerable historical centres in ancient towns, where buildings are placed very close each other. Even though a disconnection between the superstructures exists, the response of their foundations (and that of the buildings themselves) may be coupled due to the continuity of the soil underneath. Consequently, the overall system response may be different from that predicted with reference to the simple scheme of an isolated footing or building. In the performed numerical study, the soil-foundation impedance functions of a single foundation were firstly compared to well-known literature closed-form solutions to validate the procedure from a numerical viewpoint. The analyses were then repeated with adding another footing identical to the first one and placed at a varying distance from it. The comparison between the response of the master foundation when modelled as isolated and as part of a group shows that the dynamic impedances of the footing in-group may remarkably change with respect to those of the isolated foundation. In particular, the stiffness (real part) increases at a frequency depending on footing-footing distance and the damping ratio increases or decreases depending to the type of imposed oscillation.
\end{abstract}

Keywords: Soil-structure interaction, Dynamic Cross Interaction (DCI), Impedance functions, Shallow foundation, 3D numerical modelling 


\section{INTRODUCTION}

With the rapid progress of urbanization, very closely-spaced buildings are increasingly being built in both large cities and smaller towns. The proximity among buildings could produce an interaction between them and, consequently, may cause a different response under both static and dynamic loading. As the former aspect concerns, the cross interaction between closely spaced footings could have effects on both settlement and bearing capacity evaluation. The first author that investigated the bearing capacity problem for a group of shallow footings was Stuart (1962) [22], who proposed to insert a sort of "efficiency factors" in the bearing capacity trinomial formula proposed by Terzaghi (1943) [23]. Depending on the width B of the footing, these corrective factors may be greater than one if the two footings are placed at a short distance $\mathrm{S}$ from each other $(\mathrm{S}<3 \div 4 \mathrm{~B}$ ), equal to one in the case of higher distance ( $\mathrm{S}>4 \div 5 \mathrm{~B}$ ), so that each foundation behaves as isolated from the other, and equal to two in the case of $S=0$, i.e. when there is perfect contact between the two footings.

Under dynamic loading, the typical dynamic soil structure interaction evolves into a problem of cross interaction between multiple structures, better known in literature as Structure Soil Structure Interaction (SSSI) or Dynamic Cross Interaction (DCI). The study of SSSI may be handled with the same methods used for standard SSI problems in which a single footing (or structure) is involved. The available methods may, hence, be classified into analytical, semianalytical or numerical approaches, experimental methods with observations on prototypes. Thanks to the rapid progress of computing procedures and hardware devices, nowadays the numerical methods are the most used approach for evaluating SSSI. Menglin et al. (2011) [11] produced an extensive literature review on structure-soil-structure interaction, in which it was highlighted that the SSSI terminology was firstly introduced into the scientific literature by Luco and Contesse (1973) [9], who investigated the interaction phenomenon between two or more buildings (modelled as shear walls) placed on rigid circular foundations and subjected to obliquely or vertically incident harmonic SH-waves. Through parametric studies, Luco and Contesse (1973) [9] found that a group of closely spaced buildings could be affected by cross interaction at frequencies close to the fundamental ones of the buildings and particularly in low frequency ranges. Any vibrating foundation was found to spread a wave field that could be seen as a disturbance affecting the adjacent foundations. In [9] the dynamic excitation was represented as an external load or a seismic wave field. In the first case, the response of the foundation was assessed through the frequency-dependent soil-foundation dynamic impedance, representing the soil-foundation response to the inertial action transmitted by the superstructure and linking the force (or moment) acting on the foundation to its displacement (or rotation). In the second case, the motion at the base of the structure was determined.

Based on the substructure method, Betti (1997) [19] proposed a methodology for the analysis of the 3D cross-interaction between two massless, rigid and embedded foundations. In the lowfrequency range, the translational, rocking and torsional components of the impedance matrix show clear effects of cross-interaction, which tend to disappear as the frequency and distance between the adjacent foundations increase. Regarding the foundation input motion associated with incoming SH-, P-, and SV-waves, the case of vertically propagating waves is very indicative of the cross-interaction effects. With respect to each other, the two foundations present displacement and rotational components that are either in phase or $180^{\circ}$ out-of-phase while, with respect to the free-field soil, they move with a phase shift that varies with frequency. By increasing the distance between the two foundations, each component of the foundation input motion approaches the corresponding one for the case of an isolated foundation. In the horizontal direction, the displacements of the second foundations are $10 \%$ lower than the value of the 
first footing and the two foundations move completely out of phase with respect to each other and to the free field soil. For waves propagating with angles of inclination in both planes, vertical and horizontal, the motion of the two foundations becomes more complicated, showing differences in both amplitude and phase [19].

\section{DEFINITION OF THE SOIL-FOUNDATION IMPEDANCE}

Impedance functions represent the frequency-dependent stiffness and damping characteristics of the foundation-soil system, which link the forces acting on the foundation to its displacements. The typical expression of an impedance function is:

$$
S_{i j}(\omega)=\bar{K}_{i j}(\omega)+i \omega \bar{C}_{t o t, i j}(\omega)
$$

with $\mathrm{i}=\mathrm{j}=\mathrm{x}, \mathrm{y}, \mathrm{z}$ for the translational motion along the three principal axes; $\mathrm{i}=\mathrm{t}$ and without the $\mathrm{j}$-term for the rotation around $\mathrm{z}$ (torsional mode) and $\mathrm{i}=\mathrm{r}$ and $\mathrm{j}=\mathrm{x}$ or $\mathrm{y}$ for the rotation around the $\mathrm{x}$ or y axes. The dynamic stiffness $\bar{K}_{i j}$ is the product of the static stiffness $K_{i j}$ and the dynamic stiffness coefficient $k(\omega)_{i j}$, while the total damping $\bar{C}_{t o t, i j}$ is the sum of a contribution related to the soil hysteretic damping ratio $\beta$ and to the radiation damping. This latter is due to the waves scattering from the foundation and is the product of a static value $\mathrm{C}_{\mathrm{rad}, \mathrm{ij}}$ and a dynamic coefficient $\mathrm{c}_{\mathrm{rad}, \mathrm{ij}}(\omega)$.

$$
\begin{gathered}
\overline{\mathrm{K}}_{\mathrm{ij}}=\mathrm{K}_{\mathrm{ij}} \cdot \mathrm{k}(\omega)_{\mathrm{ij}} \\
\overline{\mathrm{C}}_{\text {tot }, \mathrm{ij}}=\mathrm{C}_{\text {rad,ij }} \cdot \mathrm{c}(\omega)_{\mathrm{rad}, \mathrm{ij}}+\frac{2 \overline{\mathrm{K}}_{\mathrm{ij}} \beta}{\omega}
\end{gathered}
$$

The value of each term depends on the angular frequency, $\omega$, as well as on the foundation shape and embedment. Classical solutions are provided by Gazetas (1991) [5], Pais and Kausel (1988) [1] and Mylonakis et al. (2006) [14] assuming a rigid arbitrary-shaped foundation placed on the surface of an ideal halfspace or embedded in it. Additional formulations are available in literature to account for the variation of the shear stiffness variation with depth (Gazetas, 1991[5]; Vrettos, 1999 [24]), foundation embedment (e.g., Apsel and Luco, 1987 [2]), and flexibility (e.g., Iguchi and Luco, 1982 [6]).

In the following, the second subscript $\mathrm{x}, \mathrm{y}, \mathrm{z}$ referred to the translational components of the impedances will be omitted for the sake of brevity.

\section{Numerical analysis}

This section illustrates the procedure used in the performed study for the evaluation of the impedance functions. Through a finite difference commercial code, a single footing was firstly modelled and the obtained impedances were compared to the closed-form solutions published in literature (Gazetas, 1991[5]). Later, another foundation with the same geometric and load characteristics of the master one was added. The impedances for the double footing system 
were compared to the corresponding values of the single foundation case to appreciate the crossinteraction effects.

\subsection{Details on the numerical model and load application procedure}

The 3D analysis domain (Figure 1) is a soil volume with a square plan ( $80 \mathrm{~m}$ on each side), and a height of $50 \mathrm{~m}$. Both the single (a) and the double foundations (b) were considered rectangular with a base $\mathrm{B}$ equal to $2 \mathrm{~m}$ and a length $\mathrm{L}$ of $10 \mathrm{~m}$. Three different values of spacing between the two footings were considered $(\mathrm{S}=2,1$ and $0.5 \mathrm{~m})$ so that the ratio $\mathrm{S} / \mathrm{B}$ was varied between 0.25 and 1 . In the static conditions, fixed boundaries were placed at the bottom and lateral surfaces delimitating the soil volume, while quiet boundaries were activated during the dynamic analyses to delete the reflection of the outward propagating waves and allow the necessary energy radiation towards infinity. As soil behaviour concerns, a linear visco-elastic isotropic law was assigned to all soil elements. Viscous damping was introduced in the model through the Rayleigh formulation. Soil damping was set to a very low value so that the overall damping encompassed in the numerical simulations can be assumed to be totally radiative. The presence of the groundwater was not considered, so the analyses were conducted in total stress. Table 1 shows the physical and mechanical properties assigned to the soil in the parametric analysis.

\begin{tabular}{ccc}
\hline Material prperties & Unit & Value \\
\hline Soil unit weight $\mathrm{g}$ & {$\left[\mathrm{kN} / \mathrm{m}^{3}\right]$} & 19.0 \\
Bulk modulus K & {$[\mathrm{Mpa}]$} & 12.2 \\
Shear modulus G & {$[\mathrm{MPa}]$} & 5.6 \\
Shear wave velocity $\mathrm{V}_{\mathrm{S}}$ & {$[\mathrm{m} / \mathrm{s}]$} & 54.0
\end{tabular}

Table 1: Parameters assigned to the soil in the numerical study. 
(a)

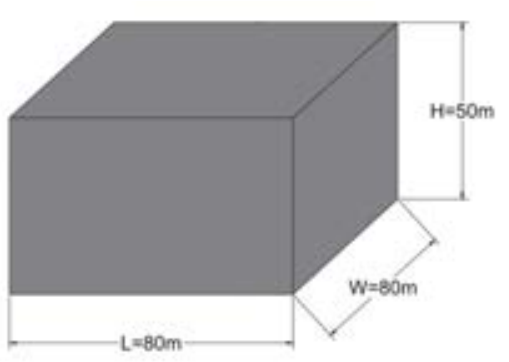

(b)

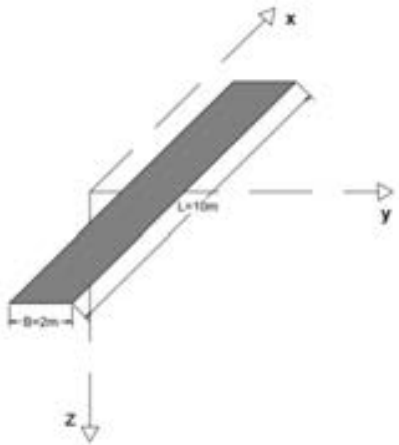

(c)

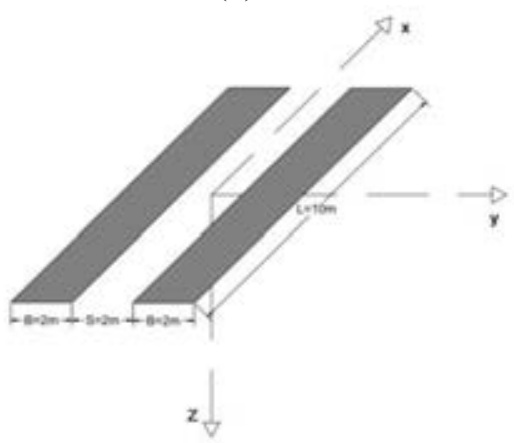

Figure 1: Analysis domain (a), single foundation (b) and double foundation system (c).

The structural element of the footing was not included within the numerical model, but its effect was accounted by applying a velocity field at all nodes placed on the foundation footprint. Since a uniform displacement field was applied to these nodes, the case of a rigid foundation $(E I \rightarrow \infty)$ was hence reproduced. In the static case, a constant velocity along $\mathrm{x}-$, $\mathrm{y}$ - or z-directions was applied to all grid points of the contact area in order to calculate the corresponding translational stiffness components. To obtain the rotational stiffness, nodal velocities varying with a linear distribution with respect to the $\mathrm{x}$ and $\mathrm{y}$ axes of the footing and null in correspondence of the centre of the foundation were imposed. In this way, the moment acting around each horizontal axis was simulated. In the dynamic case, a harmonic function of velocity $[\mathrm{v}(\mathrm{t})=\omega \mathrm{A} \cos (\omega \mathrm{t})]$ has been applied, so that the imposed displacement $s(t)$ is harmonic too and given by:

$$
s(t)=A \operatorname{sen}(\omega t)
$$

where $A$ is the oscillation amplitude and the circular frequency $\omega$ is linked to frequency $f$ by the well-known relation, $\omega=2 \Pi f$. Different values of the input frequency $f$ were considered that is $1,3,5,7,9,11$ and $13 \mathrm{~Hz}$. By imposing the harmonic velocity time-history at all nodes of the loaded area, the induced stress state is also harmonic, with an amplitude depending on the soil stiffness and out of phase with respect to the displacement due to all damping sources present in the model.

\subsection{Interpretation method}

By calculating the resultant of the contact stresses, the static stiffness in the vertical direction was obtained as:

$$
K_{z}=\frac{F}{\delta}=\frac{\sum_{i=1}^{N} \sigma_{z z i} A_{i}}{\delta}
$$

where $A_{i}$ represented the area of the mesh elements below the loaded footprint, $\sigma_{z z i}$ the contact pressure at the i-th node of the loaded area and $\delta$ the displacement at the footing centre. The values obtained numerically were compared to those provided by the available literature solutions (Gazetas, 1991). For the other translational degrees of freedom (d.o.f.) of the footing, the static stiffnesses were calculated with the same procedure described above for the vertical direction.

The rotational stiffness was calculated as the ratio between the moment, $\mathrm{M}$, and the applied rotation, $\theta$ : 


$$
K_{r y}=\frac{M}{\vartheta}=\frac{\sum_{i=1}^{N} \sigma_{z z i} y_{i} A_{i}}{\vartheta}
$$

and

$$
K_{r x}=\frac{M}{\vartheta}=\frac{\sum_{i=1}^{N} \sigma_{z z i} x_{i} A_{i}}{\vartheta}
$$

The moment has been obtained through integration of the vertical stresses computed below the foundation footprint, multiplied by the distance from the rotation axis, i.e. $\mathrm{y}_{\mathrm{i}}$ or $\mathrm{x}_{\mathrm{i}}$. The rotation has been obtained as ratio between the vertical displacement obtained at the edge of the foundation footprint and the half-length (in $\mathrm{x}$ and $\mathrm{y}$ direction) of the foundation itself.

To obtain the impedance functions in the frequency domain, the Fourier transforms of the displacement and of the force were required. Having imposed a given velocity (therefore, a displacement) and not a load, it was better to calculate firstly the soil-foundation flexibility (inverse of stiffness) and then the impedance matrix as the inverse of the flexibility. As it is well known, the dynamic stiffness and damping correspond to the real and the imaginary parts of the impedance.

\section{RESULTS}

\subsection{Static case}

In Table 2, the static stiffnesses computed through the procedure described above have been compared to those provided by Gazetas (1991) [5] closed-form equations. In the last column of Table 2, the percentage of variation between numerical and analytical values for each d.o.f. are listed. The analytical values were obtained by considering a single strip footing placed on a homogeneous half space with the same parameters reported in Table 1. From Table 2, it can be observed that the obtained numerical predictions are in good agreement with the values provided by the literature formulations, especially for the vertical and rotational degrees of freedom. The higher mismatch may be observed on the translational mode along $\mathrm{x}$ and $\mathrm{y}$ directions.

\begin{tabular}{cccc}
\hline & Numeric value calculated & Gazetas (1991) & Variation (\%) \\
\hline $\mathrm{K}_{\mathrm{z}}[\mathrm{N} / \mathrm{m}]$ & $9.62 \mathrm{E}+07$ & $9.85 \mathrm{E}+07$ & -2.33 \\
$\mathrm{~K}_{\mathrm{y}}[\mathrm{N} / \mathrm{m}]$ & $6.47 \mathrm{E}+07$ & $8.75 \mathrm{E}+07$ & -26.06 \\
$\mathrm{~K}_{\mathrm{x}}[\mathrm{N} / \mathrm{m}]$ & $6.07 \mathrm{E}+07$ & $7.69 \mathrm{E}+07$ & -21.07 \\
$\left.\mathrm{~K}_{\mathrm{ry}} \mathrm{Nm} / \mathrm{m}\right]$ & $1.38 \mathrm{E}+09$ & $1.46 \mathrm{E}+09$ & -5.48 \\
$\left.\mathrm{~K}_{\mathrm{rx}} \mathrm{Nm} / \mathrm{m}\right]$ & $1.25 \mathrm{E}+08$ & $1.28 \mathrm{E}+08$ & -2.30 \\
\hline
\end{tabular}

Table 2: Comparison between the static stiffness obtained through the developed numerical procedure and solutions proposed by Gazetas (1991)

Figure 2 shows the results obtained for the system of two identical footings placed at different distance $\mathrm{S}$ between them. On the vertical axis of both figures, there is the percentage of variation of the translational (a) and rotational (b) static stiffness of the master footing when considered as part of a group and when considered alone. Since this percentage for all swaying motions and rotational $\mathrm{K}_{\mathrm{ry}}$ are negative, the static stiffness of the footing in a group, as expected, is always smaller than that of the same foundation considered isolated ( $\left.\mathrm{K}_{\text {double }}<\mathrm{K}_{\text {single }}\right)$. In addition, for all modes the static stiffness of the master footing in a group decreases with decreasing the ratio S/B due to cross interaction effects. Singular is the case of the rotational 
stiffness $\mathrm{K}_{\mathrm{rx}}$ (long side of the footing), which is always positive $\left(\mathrm{K}_{\mathrm{rx} \_ \text {double }}>\mathrm{K}_{\mathrm{rx} \_ \text {static }}\right)$ and seems poorly affected by cross interaction when $\mathrm{S} / \mathrm{B}$ is equal to 0.25 .

(a)

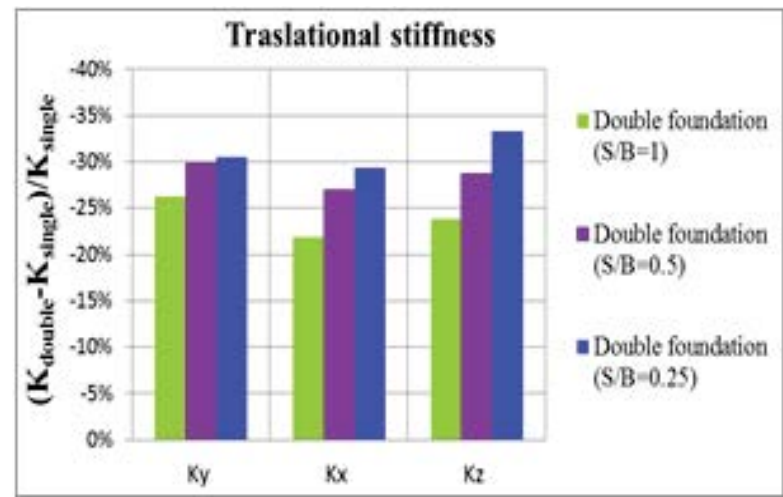

(b)

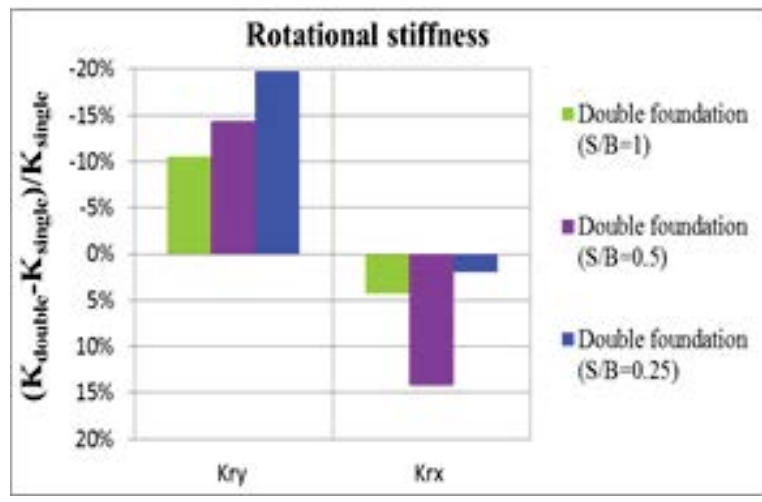

Figure 2: Static stiffness of the master foundation in group (double) or isolated (single) for the translational (a) and rotational (b) component of motion.

\subsection{Dynamic case}

The variation of the dynamic coefficients against the dimensionless frequency $a_{0}=\omega B / V s$ are plotted in the Figures 3-7 for different distance ratios, S/B. In addition, the impedances obtained numerically and analytically for the isolated footing have been superimposed for comparison.

For a single foundation, the obtained results (red line) are in excellent agreement with the analytical values (black line) provided by Gazetas (1991) equations up to a dimensionless frequency $\mathrm{a}_{0}$ equal to 1 . For $\mathrm{a}_{0}>1$, a slight mismatch is observed for the horizontal translational modes (Figures 4 and 5). Similar observations may be drawn for the radiation damping coefficients. The damping coefficients $\mathrm{c}_{\mathrm{rx}}$ and $\mathrm{c}_{\mathrm{ry}}$ (Figures 6 and 7), instead, are slightly higher than those obtained analytically in the whole range of dimensionless frequency $a_{0}$. In short, for the single footing the differences between the numerical and analytical predictions are quite small, so that the overall developed numerical procedure may be considered reliable.

With reference to the twin footing system, it can be observed that the impedances of the master foundation in the group are close to those of the single footing for low values of the frequency a. Conversely, there is a systematic increase of the stiffness coefficient for the footing in the group at higher frequencies, except for the rotational d.o.f. around the x-axis (long side in Figure 6). The dimensionless frequency at which the presence of an additional footing influences the results decreases with increasing S/B. Actually, the interference occurs when the wave originated from the clone foundation forces the master one to move out of phase with respect to its original motion. Such effect depends on the forcing frequency and on the S/B ratio. In fact, longer wavelengths, associated to lower frequencies, make closely-spaced foundations with smaller $\mathrm{S} / \mathrm{B}$ (e.g., $\mathrm{S} / \mathrm{B}=0.25$ ) to move together without altering the response with respect to the isolated case. This means that closer are the foundations, higher is the frequency at which they interfere. No relevant differences may be recognized with changing the degree of freedom of the foundation.

The damping coefficients of the twin footing tend to increase with respect to that of the single foundation for the vertical motion (Figure 3) and this increase is proportional to S/B. Only for $\mathrm{S} / \mathrm{B}=1$ there is a decrease starting from $\mathrm{a}_{0}=1$, i. e. for a $\mathrm{f}=9 \mathrm{~Hz}$. The same trend is observed for the rotational d.o.f. around the y axis (Figure 7) and the opposite trend results for 
the other translational components of motion (Figure 4 and 5). Such differences are associated to the fact that the wavefront originated by the twin footings interfere in a constructive or destructive way depending on the type of waves generated by the foundation motion.

(a)

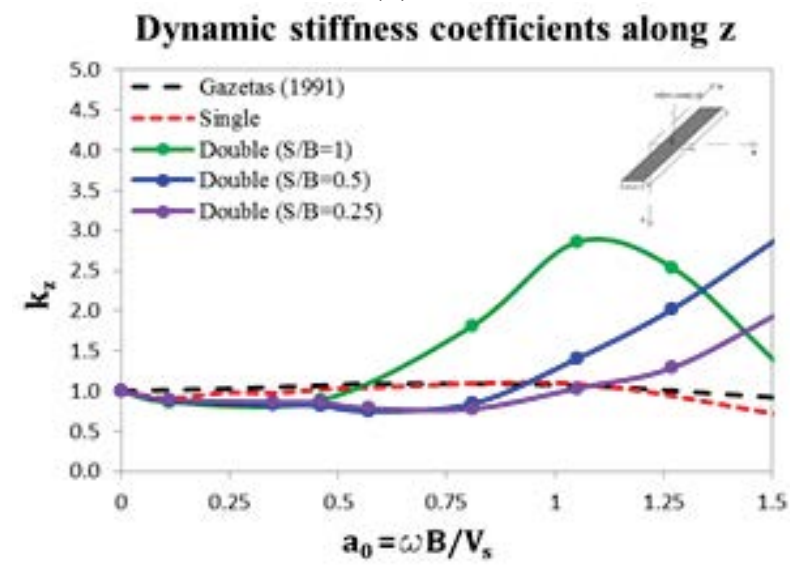

(b)

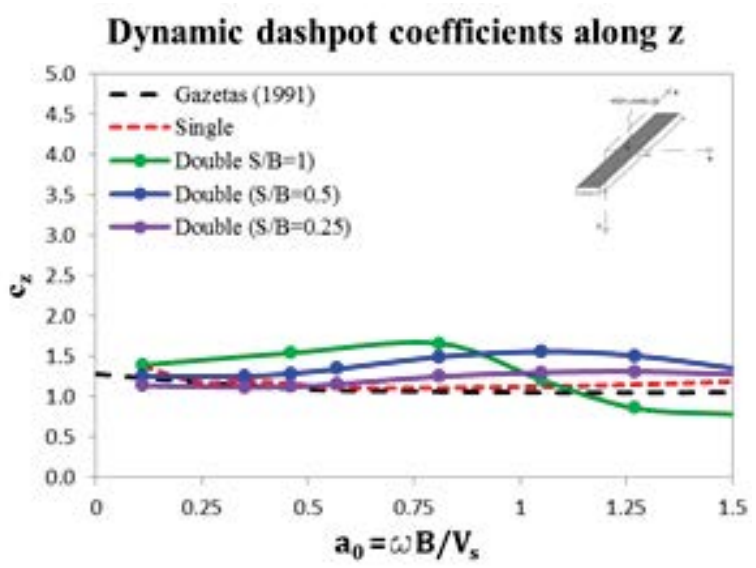

Figure 3: Vertical dynamic stiffness coefficients (a) and damping coefficients (b).

(a)

Dynamic stiffness coefficients along y (short side)

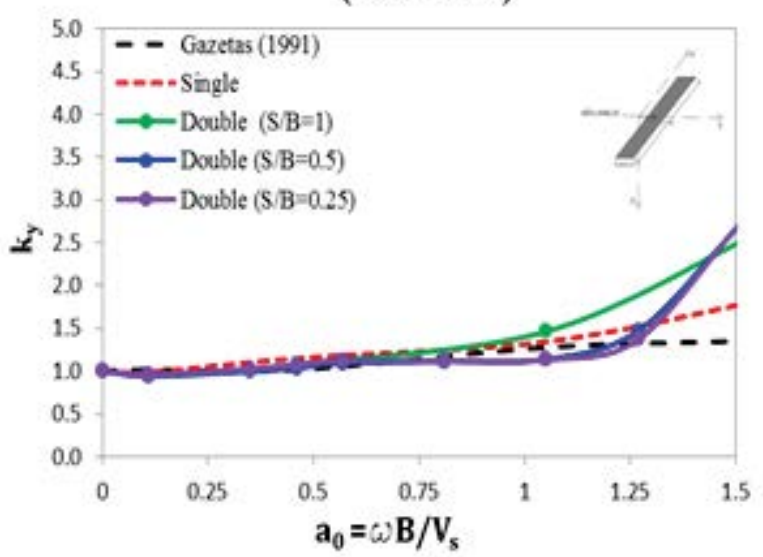

(b)

\section{Dynamic dashpot coefficients along $y$}

(short side)

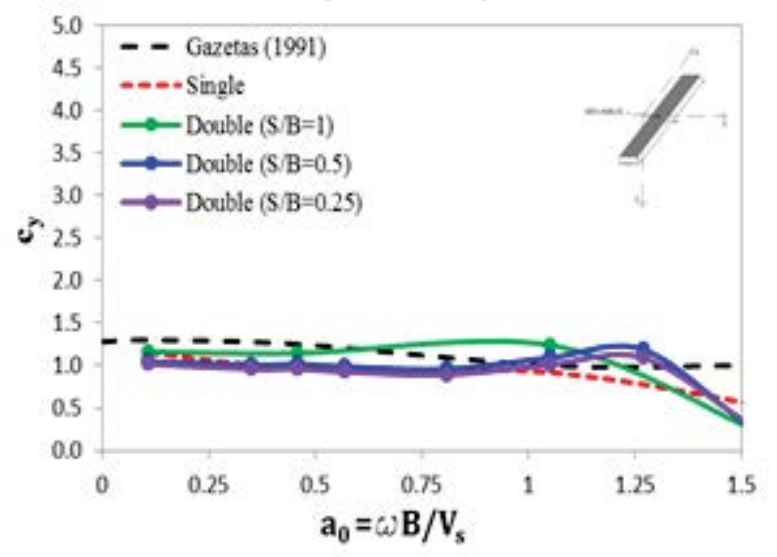

Figure 4: Horizontal dynamic stiffness coefficients (a) and damping coefficients (b) along short side. 
(a)

Dynamic stiffness coefficients along $x$ (long side)

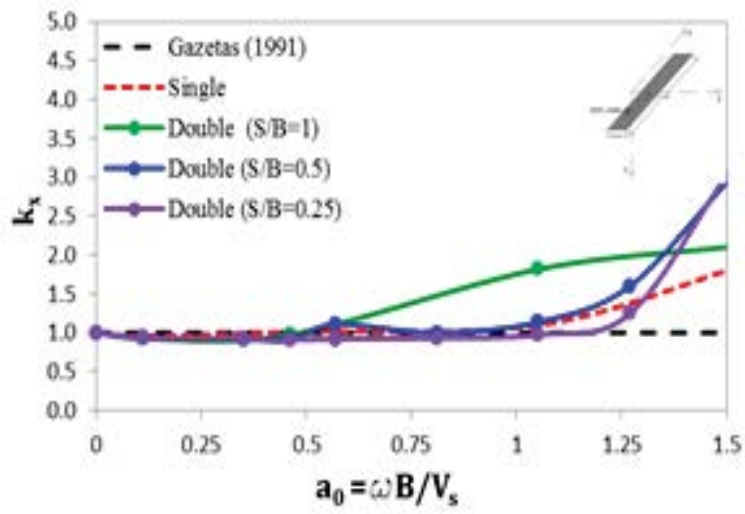

(b)

Dynamic dashpot coefficients along $\mathbf{x}$ (long side)

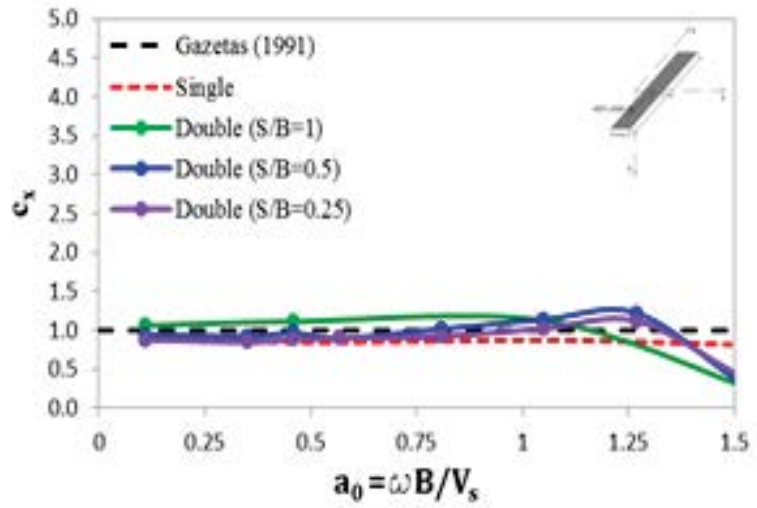

Figure 5: Horizontal dynamic stiffness coefficients (a) and damping coefficients (b) along long side.

(a)

Dynamic stiffness coefficients around

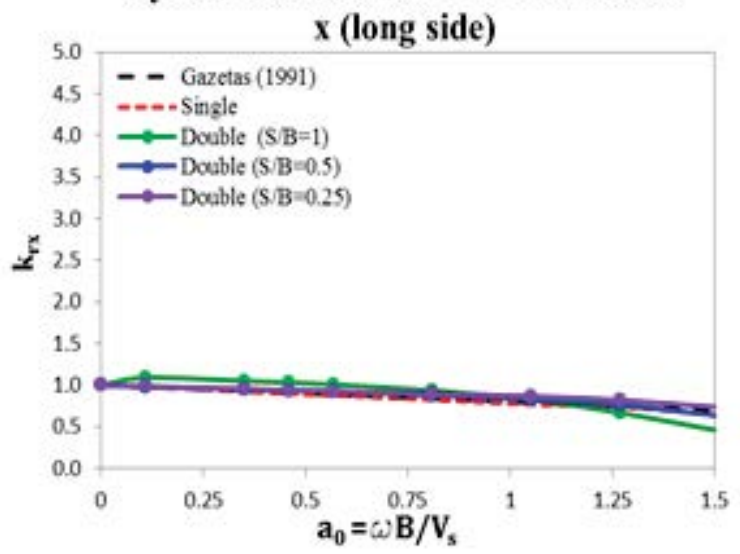

(b)

Dynamic dashpot coefficients around $x$

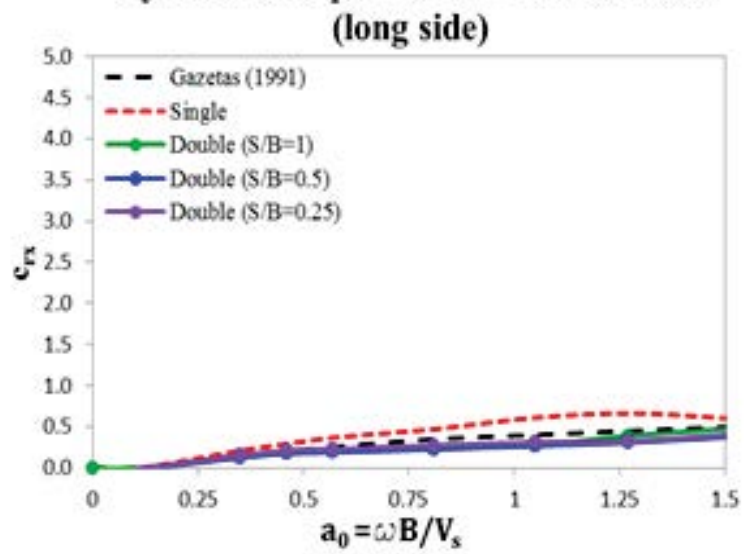

Figure 6: Rotational dynamic stiffness coefficients (a) and damping coefficient (b) around long side. 
(a)

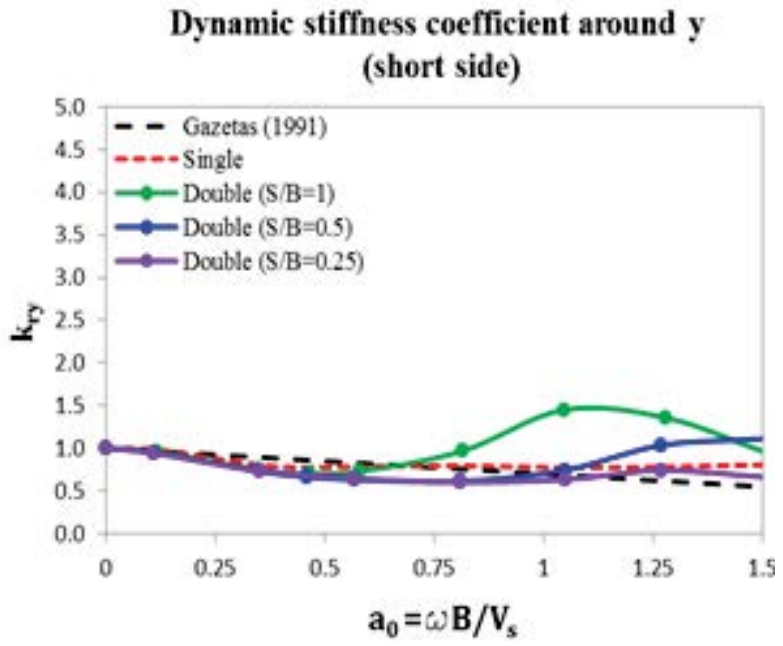

(b)

Dynamic dashpot coefficient around $y$

(short side)

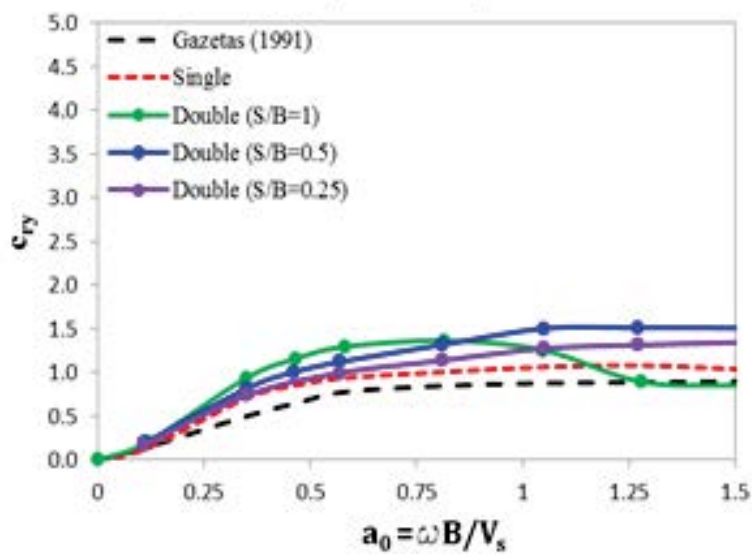

Figure 7: Rotational dynamic stiffness coefficients (a) and damping coefficients (b) around short side.

\section{CONCLUSIONS}

The static and dynamic cross interaction between two closely-spaced shallow foundations was numerically investigated through a numerical procedure based on the finite difference technique. The cases of a single foundation and of two identical footings placed on the surface of a viscoelastic half-space were solved numerically.

For the single foundation case, the impedance functions thus obtained successfully reproduced those provided by Gazetas (1991) solutions.

For the twin foundation case, lower values of the static stiffness were found for almost all degrees of freedom due to cross-interaction effects. The dynamic stiffness coefficients were found coincident with those of the single foundation at low oscillation frequencies. Higher values were, instead, obtained for a typical dimensionless input frequency that markedly depends on footing-footing distance ratio $\mathrm{S} / \mathrm{B}$. The dynamic damping coefficients increase or decrease with respect to that of the single footing depending on the type of oscillation mode of the foundation. As a future perspective of the study, the current parametric study could be enriched with considering different configurations of the footing group, different values of soil damping, stiffness, foundation embedment and type of loading.

\section{REFERENCES}

[1] Pais A., Kausel E., "Approximate formulas for dynamic stiffnesses of rigid foundations", Soil Dynamics and Earthquake Engineering 7 (4), 213-227

[2] Apsel R. J. and Luco J., "Impedance functions for foundations embedded in a layered medium: An integral equation approach.” Earthquake Engineering \& Structural Dynamics 15 (1987): 213-231.

[3] Braja M. Das and Larbi-Cherif Said, Bearing capacity of two closely-spaced shallow foundations on sand, Soils and Foundations, Vol.23, No. 1, (1983)

[4] Vicencio F., Alexander N. A., Dynamic structure-soil-structure interaction in unsymmetrical plan buildings due to seismic excitation, Soil dynamics and earthquake engineering 127, 105817, (2019) 
[5] Gazetas, G. 1991, Formulas and charts for impedances of surface and embedded foundations, Journal of Geotechnical Engineering, 117(9), pp.1363-138.

[6] Iguchi M. and Luco J., Dynamic response of flexible rectangular foundations on an elastic half-space, Earthquake Engineering \& Structural Dynamics 9 (1981): 239-249.

[7] Knappett J. A., Madden P., Caucis K., Seismic structure-soil-structure interaction between pairs of adjacent building structures, Géotechnique 65, No 5, 429 - 441, (2015)

[8] Lee J., Eun J., Estimation of bearing capacity for multiple footings in sand, Computers and Geotechnics, 36, 1000-1008, (2009)

[9] Luco JE, Contesse L., Dynamic structure-soil-structure interaction, Bulletin of the Seismological Society of America 1973;63(4):1289-303.

[10] Wang J., Zhou D., A simple model for vertical dynamic interaction among a group of strip footing rested on homogeneous half-space, Shock and vibration Article ID 7382392 , 12 pages, (2018)

[11] Menglin L., Huaifeng W., Xi C., Yongmei Z., Structure-soil-structure interaction: lit erature review, Soil Dynamics and Earthquake Engineering Vol. 31, 1724 - 1731, (2011)

[12] Alwalan M. F., Interaction of closely spaced shallow foundations on sands and clays: a review, International journal of advanced engineering research an science, vol.-5, issue 9, sept. (2018)

[13] Pecce M.R., Sica S., Ceroni F., Principe B., Soil-Structure interaction: the case study of a masonry tower, NUMGE 2, pp. 1163-1168, (2014)

[14] Mylonakis G., Nikolaou S., Gazetas G. (2006), Footings under Seismic Loading: Analysis and Design Issues with Emphasis on Bridge Foundations, Soil Dynamics and Earthquake Engineering, 26(9): 824-853

[15] Gosh P., Sharma A., Interference effect of two nearby strip footings on layered soil: theory of elasticity approach, Acta Geotechnica, 5:189-198, (2010)

[16] Gosh P., Rajesh S., Sai Chand J., Linear and nonlinear elastic analysis of closely spaced strip foundations using Pasternak model, Frontiers of Structural and Civil Engineering, 11(2): 228-243, (2017)

[17] Prandtl L. (1921), Über die Eindringungsfestigkeit (Härte) plastischer Baustoffe unddie Festigkeit von Schneiden, Zeit Angew Math Mech, (1):15 20.

[18] Ge Q., Xiong F., Xie L., Chen J., Yu M., “Dynamic interaction of soil-structure cluster”, Soil dynamics and earthquake engineering 123, 16 - 30, (2019)

[19] Betti R., Effects of the dynamic cross-interaction in the seismic analysis of multiple embedded foundations, Earthquake engineering and structural dynamics Vol. 26, 1005 - 1019 (1997)

[20] Sica S., Interaction between closely spaced strip footing, wp16-sub task-16.3.3.-ur7 (Sannio-Sica), (2019).

[21] Tileulioglu S., Stewart J. P., Nigbor R. L., Dynamic stiffness and damping of a shallow foundation from forced vibration of a field test structure, Journal of geotechnical and geoenvironmental engineering, April (2011) 
[22] Stuart JG., Interference between foundations, with special reference to surface footings in sand, Geotechnique 1964;12(1):15-20.

[23] Terzaghi, K. (1943), Theoretical Soil Mechanics, Wiley, New York.

[24] Vrettos C., Vertical and rocking impedance for rigid rectangular foundations on soils with bounded non-homogeneity, Earthquake Engineering \& Structural Dynamics 28(12):1525 1540 (1999) 